\title{
A GLACIAÇÃO PROTEROZÓICA NO CENTRO-NORTE DE MINAS GERAIS
}

\author{
MANFRED HETTICH*
}

\begin{abstract}
Metasediments of the proterozoic Macaúbas Group (São Francisco Supergroup) occur in great distribution and thickness (about $1000 \mathrm{~m}$ ) in the Upper Jequitinhonha Area. Other occurrences in Minas Gerais are found in narrow belts around the Serra do Cabral and at the western border of the Serra do Espinhaço. In the Jequitinhonha Area the sequence can be subdivided into the following lithostratigraphic units (from base to top): basal quartzites and conglomerates, pebbly metagreywackes, an alternation (sometimes graphite and manganese bearing) of phyllites, metasiltstones and quartzites, fine to medium grained quartzites and finally green schists. The metagreywackes, which were identified as tillites, show transitions of facies towards the southeast from continental tillites over aquatillites to glacial-marine sediments. Other criteria favouring a proterozoic glaciation are: grooved and polished pavements, one esker, one varved slate, and striated and facetted pebbles in flat iron form and with gouge marks. Stratigraphic, faciologic and paleostructural relationships not yet studied in detail, indicate an interfingering between the metasediments of the Bambuí and the Macaúbas.
\end{abstract}

INTRODUÇÃo Os metassedimentos proterozóicos do Grupo Macaúbas, anteriormente reunidos com o Conglomerado Sopa na Série Lavras e, depois, reconhecidos como unidade mais nova, cobrem uma grande área no norte de Minas Gerais. Estratigraficamente o Macaúbas posiciona-se acima do Supergrupo Espinhaço/Minas, do qual é separado, geralmente, por falhas de empurrão ou por discordância angular. Sua relação frente ao Grupo Bambuí, também proterozóico, ainda é discutida. Vários autores julgam o Bambuí como uma unidade mais nova, enquanto outros acreditam que as duas unidades sejam mais ou menos contemporâneas. Os grupos Bambuí e Macaúbas compõem o Supergrupo São Francisco.

Há mais de 50 anos discute-se a origem glacial do Macaúbas, no qual acharam-se rochas semelhantes a tilitos e, às vezes, seixos com formas características. Essa opinião, por falta de critérios válidos e pelo desconhecimento da estratigrafia da seqüência, era uma hipótese, até a descoberta de um pavimento estriado, na Serra do Cabral, em 1967. Porém, logo depois, foi posta em dúvida a origem glacial das rochas conglomeráticas e o pavimento estriado foi interpretado como de origem tectônica. Retomando a hipótese glacial, mapeando e subdividindo litoestratigraficamente o Macaúbas, na região do Alto Jequitinhonha, o autor investigou inúmeros afloramentos na borda ocidental da Serra do Espinhaço, na Serra do Cabral e na área mencionada. As evidências descobertas são tão convincentes que a origem glacial de uma parte do Macaúbas não pode mais ser posta em dúvida.

Distribuição dos metassedimentos Macaúbas Os metassedimentos do Grupo Macaúbas ocorrem, em Minas Gerais:

em uma faixa estreita em torno da Serra do Cabral e ao norte de Jequitaí; em faixa, também estreita, acompanhando a borda ocidental da Serra do Espinhaço

${ }^{*}$ GEOSOL - Geologia e Sondagens Ltda. Rua Aimorés, n. ${ }^{\circ} 200.30000$ - Belo Horizonte (MG) 


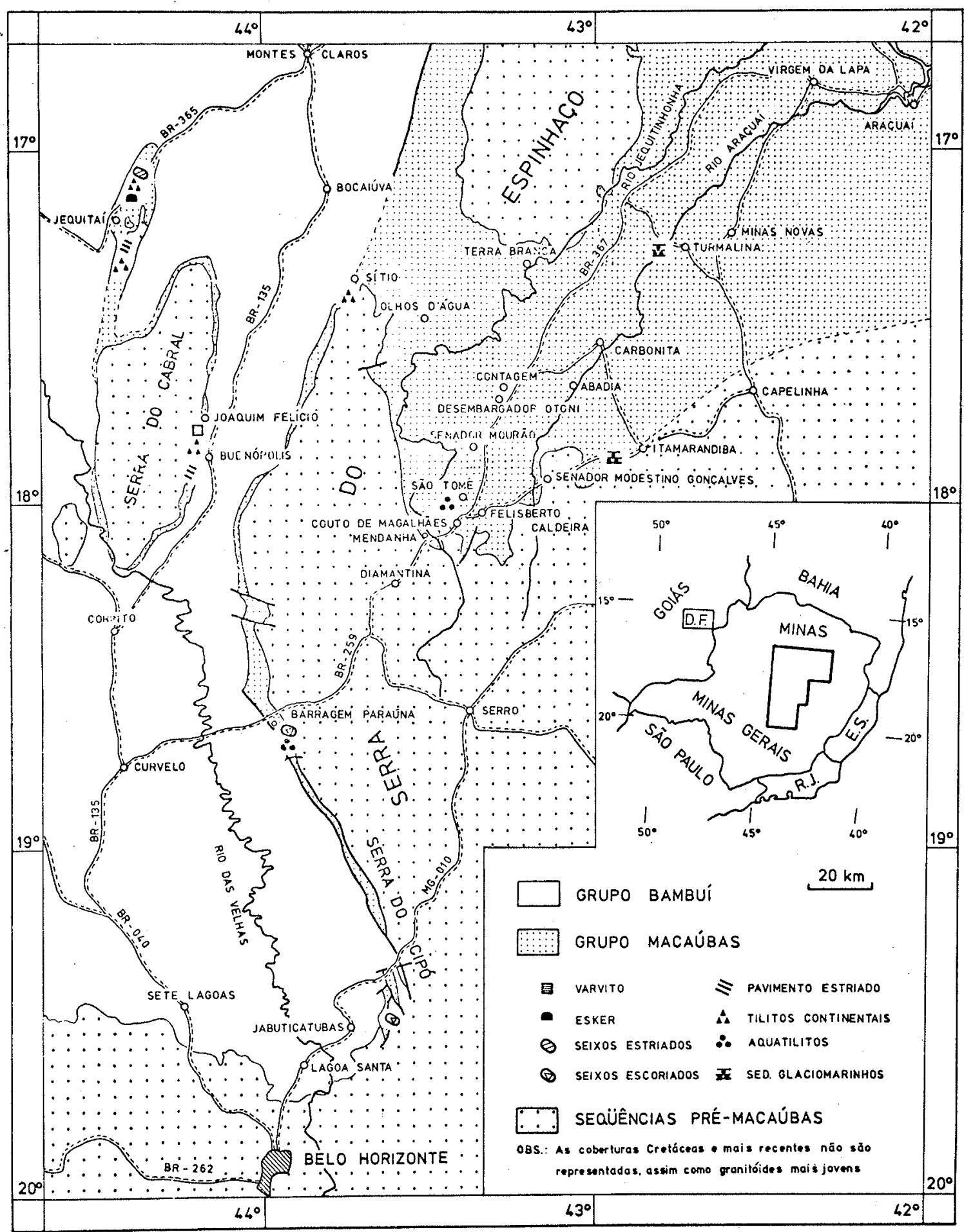

Figura 1 - Esboço geológico regional mostrando os relictos glaciais e o posicionamento das localidades mencionadas no texto 
Meridional e Central, desde Jabuticatubas, ao sul, até a divisa com o Estado da Bahia, em uma extensão meridional de $500 \mathrm{~km}$;

em distribuição maior (aproximadamente $100 \times 350 \mathrm{~km}$ ) na região do Alto Jequitinhonha e do Rio Araçuaí, entre Couto de Magalhães e a divisa com a Bahia.

Estratigrafia A seqüência atinge maior espessura na região do Alto Jequitinhonha e do Rio Araçuaí, no triângulo Couto de Magalhães-Itamarandiba-Carbonita. Aí foi cartografada, em 1971/72, uma área de $3000 \mathrm{~km}^{2}$ na escala de 1:60000; na parte ocidental, - Macaúbas, pela primeira vez, foi subdividido em unidades litoestratigráficas (Hettich, 1973, 1975). A área é limitada pelos meridianos $43^{\circ}$ e $43^{\circ} 30^{\prime} \mathrm{W}$ e os paralelos $17^{\circ} 30^{\prime}$ e $18^{\circ} \mathrm{S}$. Da base para o topo, encontram-se as unidades destacadas a seguir.

UNIDADE A Quartzitos basais, na maior parte grossos a microconglomeráticos, com uma espessura de 150 a $200 \mathrm{~m}$, sobrepondo, geralmente, os quartzitos do Supergrupo Espinhaço em discordância angular. Freqüentemente encontra-se estratificação cruzada. Os quartzitos são caracterizados por intercalações em forma de camadas e/ou lentes de conglomerados, com espessura desde $0,5 \mathrm{~m}$ a alguns metros. No conglomerado, os seixos, constituídos de quartzo e quartzito, mostram boa seleção e bom arredondamento e possuem diâmetro médio de $2,5 \mathrm{~cm}$. O diâmetro máximo não ultrapassa $10 \mathrm{~cm}$. Os melhores afloramentos são achados nos arredores de São Tomé e de Senador Mourão. Localmente não se observam quartzitos na base do Macaúbas. Porém, nesse caso, supõe-se a presença de falhas entre o Supergrupo Espinhaço e o Grupo Macaúbas.

A unidade $\mathrm{A}$, na região ocidental da área mapeada, foi interpretada como uma formação costeira. Sua ausência no oeste (Serra do Cabral, Jequitaí) e a falta de intercalações conglomeráticas no leste (Turmalina) corroboram essa interpretação. Além disso, as rochas da unidade $\mathrm{B}$, sobreposta, mostram, na mesma área, uma transição de fácies continental para fácies marinha. Essa hipótese foi confirmada por análises de minerais pesados, realizadas pelo pessoal da CNEN, em quartzitos ao norte de Medanha. Os quartzitos, que pertencem à unidade $\mathrm{A}$, foram interpretados como depósitos de praia (Ramos e Maciel, 1974). Recentemente (W. U. Schöll, comunicação verbal) achou-se calcário intercalado em quartzitos da unidade A entre o Rio Jequitinhonha e São Tomé. Trata-se de recifes de algas.

UNIDADE B Com aproximadamente $200 \mathrm{~m}$ de metagrauvacas com seixos, geralmente não-estratificadas. Na literatura especializada, foram designadas como conglomerados, brechas, tilitos, diamictito (Isotta, Rocha-Campos e Yoshida, 1969), metagrauvaca conglomerática (Schmidt, 1972, Gorlt, 1972), ou mixtito (Karfunkel e Karfunkel, 1975). A cor da rocha é cinza-azulada; quando decomposta, avermelhada. A matriz, descrita microscopicamente por autores antigos, foi redescrita por Gorlt (1972), Schmidt (1972), Hettich (1973, 1975) e Karfunkel e Karfunkel (1975). A unidade contém seixos e matações com tamanho máximo de $60 \mathrm{~cm}$, não-selecionados e não-classificados. Os seixos apresentam todos os graus de arredondamento e são de quartzito, quartzo opalino, rocha carbonática, rocha pelítica, gnaisse, granito e rocha básica. As metagrauvacas são desenvolvidas tipicamente na região de Couto de Magalhães. Ali se encontra uma camada de quartzito com $10 \mathrm{~cm}$ de espessura, intercalada com metagrauvaca e indícios de estratificação em forma de estruturas perturbadas que se formaram através de pequenos deslizamentos subaquáticos. Para leste, na região de Itamarandiba e de Turmalina, as rochas tornam-se estratificadas. Consideramo-las de origem glacial e glaciomarinha, respectivamente. 
UNIDADE C Formada por uma alternância de filitos, metassiltitos e quartzitos, em parte com seixos esporádicos, com uma espessura de 200 a $300 \mathrm{~m}$. Nessa unidade, são características as camadas grafitosas (tipicamente desenvolvidas em Carbonita e Abadia) e/ou manganíferas, sobre as quais se encontram localmente enriquecimentos superficiais de óxidos de manganès ( $6 \mathrm{~km}$ a $\mathrm{SE}$ de Senador Modestino Gonçalves). Raras vezes ocorrem quartzitos carbonáticos (entre Senador Mourão e São Tomé) ou rochas carbonáticas relativamente puras (Fazenda Cannabrava, a $12 \mathrm{~km}$ a leste de Abadia), que já foram descritas por Moraes et al. (1937). No leste da área mapeada, os filitos e metassiltitos transicionam para quartzo-biotita-muscovita xistos ou quartzo-muscovita xistos, nos quais pode ocorrer carbonato em lugar da mica e, em muitos casos, o carbonato pode ser o componente principal.

UNIDADE D Com $300 \mathrm{~m}$ de quartzitos finos a médios, às vezes com estratificação cruzada. Na parte superior, acham-se, em vários níveis, magnetita e, em lâminas intercaladas, material argiloso esverdeado.

UNIDADE E Xistos verdes (tremolita-epídoto-clorita xistos) com espessura estimada de 50 a $150 \mathrm{~m}($ ?). Às vezes observam-se intercalações de lâminas finas de quartzo dentrítico. Os melhores afloramentos situam-se em Felisberto Caldeira e na região de Desembargador Otoni e de Contagem (Planalto de Minas). Segundo Gorlt (1972), trata-se de tufos básicos.

UNIDADE $\mathrm{F}$ Com mais de $200 \mathrm{~m}$ de quartzitos com granulação fina a média, às vezes finamente laminados. Os quartzitos foram observados sobrejazendo os xistos verdes, a leste de Contagem. Porém, segundo novos levantamentos nesta área, os quartzitos parecem ter sido deslocados por uma falha inversa e são, provavelmente, mais velhos (unidade D) que os xistos verdes. Nesse caso, os xistos verdes formariam a unidade mais nova do Macaúbas. Karfunkel e Karfunkel (1975), no entanto, descrevem metassiltitos acima dos xistos verdes, $40 \mathrm{~km}$ ao norte.

Em princípio, a mesma seqüência (com alterações faciológicas) foi descrita por Karfunkel e Karfunkel (1975) na região de Terra Branca-Grão Mogol. Nas bordas da Serra do Cabral e na região de Jequitaí, ocorre apenas a unidade B (mas com espessura menor), intercalada entre o Grupo Bambuí e o Supergrupo Espinhaço. Na borda ocidental da Serra do Espinhaço Meridional (Serra do Cipó), ocorrem as unidades A, B e C (Hettich e Karfunkel, 1977, em publicação), enquanto que, mais para o norte (Barragem do Paraúna), a unidade $\mathrm{C}$ está faltando. A espessura dos metassedimentos dó Grupo Macaúbas atinge poucos metros nas bordas da Serra do Cabral e aproximadamente $1000 \mathrm{~m}$ na região do Alto Jequitinhonha.

Revisão bibliográfica sobre a glaciação no Macaúbas Depósitos glaciais foram mencionados, pela primeira vez, por Hartt (1870) na região de Minas Novas, no nordeste de Minas Gerais. Hartt, no entanto, não reconheceu as rochas glaciais do Macaúbas, presentes na região. Posteriormente, aqueles depósitos, que Hartt considerou como Pleistocênicos, foram caracterizados como depósitos de tálus por Moraes (1932). Lisboa (1906) publicou fotos de seixos facetados encontrados na região de Abaeté, no oeste de Minas Gerais, e discutiu a formação glacial. Porém a procedência dos seixos não foi determinada. Em 1881, Derby descreveu o Conglomerado Jequitaí, para o qual Branner (1919) sugeriu origem glacial. Mais tarde, Moraes (1929) comparou o Conglomerado Jequitaí com os metasședimentos da região do Rio Jequitinhonha, denominando-os Série Lavras (já defi- 
nida por Derby, em 1905, na Ghapada Diamantina, na Bahia). Assim, foi Branner que reconkeceu primeiramente a glaciação que, hoje em dia, posicionamos no tempo como proterozóica. Contribuições anteriores, como por exemplo a de Derby (1888), relacionam-se com a glaciação permocarbonífera no sul do Brasil. Porém, segundo Moraes (1932), ". . a origem glacial, para parte das rochas aqui mencionadas, foi primeiramente sugerida, de um modo claro, por Euzébio de Oliveira" (em uma comunicação verbal, em 1921, a respeito da origem glacial dos conglomerados da Série Lavras, na Bahia, citada em Moraes Rego, 1930). Moraes Rego relatou aspectos em favor de sedimentação glacial dos conglomerados que ocorrem na Série Lavras: forma de seixos, falta de classificação por tamanho, etc. $\mathrm{O}$ autor, no entanto, não achou totalmente suficientes os critérios, pois "... os vestígios indubitáveis de fenômenos de sedimentação glacial são as estrias, quer nos seixos, quer no bed-rock". Williams (1930), também, sugeriu origem glacial para os conglomerados da Série Lavras, na Bahia. Moraes e Guimarães (1930), Guimarães (1931) e Moraes (1932, 1937) subdividiram a Série Lavras em duas formações, Sopa e Macaúbas, e consideraram-nas como fluvioglacial e glacial, respectivamente. Essa interpretação baseou-se, em parte, na insuficiência dos critérios, até ali encontrados, a favor de uma origem glacial para esses metassedimentos. Pflug $(1963,1965)$ demonstrou que os conglomerados diamantíferos da Formação Sopa ocorrem na parte inferior do Supergrupo Espinhaço, do qual o Macaúbas, regionalmente, é separado por uma profunda discordância angular. Pflug interpretou os conglomerados como formação de praia. Em 1949, Gomes descreveu um "folhelho várvico" na região de Jequitaí. Essa rocha foi encontrada como um único seixo rolado em uma marmita do Rio Jequitaí. Sua procedência e sua idade estratigráfica ficaram desconhecidas e a descrição petrográfica, em nossa opinião, deixa dúvida de que se trate realmente de varvito. Mesmo assim, Guimarães (1951) citou a descoberta do "varvito" e interpretou o tilito de Jequitaí como morena frontal. Segundo esse autor, também os depósitos de Itamarandiba, $160 \mathrm{~km}$ a ESE, anteriormente descritos por Moraes "... têm caracteres de morena frontal e lacustrino". Belezkij e Guimarães (1959) separaram o Macaúbas, na Serra do Cipó, em duas unidades:

a) depósitos de varvitos e de drift;

b) depósitos de morenas.

Os autores mencionados não pormenorizaram sua observação e não dão uma descrição petrográfica dos varvitos. Em 1969, Isotta et al. publicaram os primeiros critérios indubitáveis para a existência de uma glaciação: um pavimento estriado e polido, em parte coberto por um diamictito (tilito) com seixos estriados, $10 \mathrm{~km}$ ao SE de Jequitaí. Porém esse pavimento estriado já tinha sido mencionado por Campbell et al. (1967), em um relatório interno do USGS. Schmidt (1972) pôs em dúvida a origem glacial dessa rocha por falta de blocos erráticos, roche mountonnée, varvitos e seixos estriados (que Isotta et al. já descreveram, mas não documentaram fotograficamente). Ele interpretou o pavimento estriado como de origem tectônica e o tilito como depósito de mudflow. Hettich (1973, 1975) discutiu os argumentos de Schmidt e defendeu a interpretação glacial, mostrando ter ocorrido uma transição de fácies de morenas de fundo a sedimentos glaciomarinhos em direção ESE (Jequitaí-I tamarandiba). Karfunkel e Karfunkel (1975) concordaram com esse esquema. Schermerhorn (1974), um dos melhores conhecedores de sedimentos glaciais antigos, em seu trabalho "Late precambrian mixtites: Glacial and/or nonglacial?", observa: "It seems clear that the Lavras-Macaúbas, Carandaí, and related mixtites in East Brazil are tilloids, not tillites, from the detailed work by Pflug, Ebert, Schmidt and others". Pflug (1967), que seguiu, em seus primeiros trabalhos, a opinião dos autores anteriores a favor de uma glaciação, considerou o Macaúbas como fácies sinoro- 
genética, formada durante a Orogênese Minas (Espinhaço). Em 1975, Pflug e Schöll, em uma revisão com o título "Proterozoic glaciation in eastern Brazil: a review", acreditam em uma glaciação: "Widespread occurrences of tillitic rocks in Minas Gerais (19000 squ. $\mathrm{km}$ ) and Bahia indicate a major glaciation at the end of the Minas orogeny, i.e., at the beginning of the deposition of the São Francisco Supergroup". Em outro lugar os autores escrevem: "Problems still remain: striated and facetted pebbles, varved sediments and effects of glacial pushing have not been found yet. This may in part be due of structural and metamorphic overprint".

Investigação de glaciações antigas Existem inúmeras publicações, que se contradizem, sobre tilitos (de origem glacial) pré-cambrianos, tilóides (= pseudotilitos, de origem não-glacial) e rochas de aspecto tilítico (de origem desconhecida). Muitas ocorrências, antigamente julgadas como glaciais, agora são interpretadas como depósitos de mudflow. O título, freqüentemente usado, "Glaciation or subaqueous mass movements?" mostra claramente as dificuldades que ocorrem na avaliação de antigos depósitos conglomeráticos, não-estratificados. Muitas das características de tilitos também são típicas para depósitos de mudflow: presença de seixos e matacões, baixo grau de arredondamento, má classificação e má seleção dos componentes, falta de estratificação e até presença de seixos estriados. Em geral, o caráter glacial de uma rocha só pode ser deduzido por um conjunto de critérios. A seguir destacamos os critérios válidos, segundo a opinião da maioria dos autores.

1. Rocha de aspecto tilítico, sobrejazendo imediatamente um pavimento estriado e polido. Estrias, causadas por processos de slumping, podem ser confundidas com estrias glaciais. Por causa disso, alguns autores prescrevem a presença de sulcos ou caneluras no pavimento estriado: "The most diagnostic evidence of ancient glaciation is an extensive grooved and polished pavement directly beneath till-like material" (Dott, 1961); "The best evidence of continental glaciation is the occurrence of till lying on a grooved and polished pavement" (Heezen e Hollister, 1963).

2. Seixos isolados (seixos pingados) em um sedimento finamente laminado. Porém depósitos glaciomarinhos, geralmente, não localizam a área de glaciação (Schwarzbach, 1974). Diversos trabalhos (Griggs e Kulm, 1969, Menard, 1963, Hough, 1950 e outros) sobre sedimentos glaciomarinhos, mostraram que distâncias enormes podem existir entre as áreas da glaciação e aquelas da deposição de sedimentos glaciomarinhos. Assim, Chumakow (1964) considera como características mais importantes de tilitos sua posição paleofaciológica e paleoestrutural entre a área de exaração (palavra derivada de exarar = = gravar) do gelo e a área dos depósitos periglaciais e glaciomarinhos. Um exemplo clássico disso são os tilitos Dwyka, na África do Sul (Toit, 1954).

Glaciação no Macaúbas Baseando-se no que foi dito, somente uma das publicações anteriores é válida para comprovar uma glaciação no Macaúbas, ou seja, aquela de Isotta et al. (1969). O pavimento estriado descrito (quartzito do Supergrupo Espinhaço) mostra, além de outras pequenas estruturas típicas, caneluras e efeitos de polimento. Além disso, é sobreposto por um tilito contendo seixos estriados (Figs. 2 e 3). Por ocasião de uma viagem à Jequitaí, tivemos oportunidade de examinar o afloramento e não observamos evidências de origem tectônica para o pavimento estriado. Ademais, foram encontrados dois outros pavimentos estriados, na borda ocidental da Serra do Cabral, por H. D. Walde (comunicação verbal), que também examinamos. Cotejando os tilitos de Jequitaí, de Joaquim Felício e de Sítio com os depósitos correlacionáveis das regiões do Alto Jequitinhonha e de Itamarandiba, o autor verificou uma transição de fácies, segundo WNW-ESE, de tilitos verdadeiros para sedimentos glaciomarinhos, conforme segue. 
Jequitaí - Tilito não-estratificado, interpretado como morena de fundo.

Couto de Magalhães - Tilito da mesma composição com uma intercalação fina de quartzito e às vezes mostrando estruturas perturbadas, interpretadas como estratificação submetida a deslizamentos subaquáticos. Sugere-se formação marinha, porém em água rasa, provavelmente sob a cobertura de geleiras (= aquatilito) (Figs. 4, 5 e 6).

Itamarandiba - Quartzitos e metassiltitos impuros, geralmente finamente laminados e ricos em seixos (em parte, sem dúvida, seixos pingados), que, em composição, não diferem dos que ocorrem nos tilitos de Jequitaí e de Couto de Magalhães. Os depósitos são interpretados como sedimentos glaciomarinhos (Fig. 7).

A seguir são dados outros critérios a favor de uma glaciação no Macaúbas.

1. Grande extensão dos depósitos característicos que, em direção norte-sul, em Minas Gerais, atinge $500 \mathrm{~km}$. Segundo a literatura existente, cobrem grandes áreas na Bahia. Mudflows, capazes de depositar rochas semelhantes aos tilitos, são eventos bastante locais e indicam transporte sobre distâncias curtas (Heezen e Hollister, 1963). Görler e Reutter (1968) notam que a intercalação de um tilito em outros sedimentos tem que ser mais uniforme e mais constante sobre uma distância maior do que aquela de uma olistostroma. Também Chumakow (1964) observou que pseudotilitos apenas mostram ocorrência local.

2. Presença de seixos e blocos erráticos. Várias rochas afloram a grande distância dos lugares onde ocorrem nos tilitos, sob forma de seixos. A procedência dos seixos de rocha carbonática ainda não é conhecida. Sugere-se uma sedimentação de rochas carbonáticas no Gráton Sanfranciscano (Bambuí) antes da glaciação, erosão das mesmas e incorporação aos tilitos. A mudança de clima, exigida para esse processo, é comprovada pela existência de calcários nos quartzitos basais do Macaúbas na região do Alto Jequitinhonha (W. U. Schöll, comunicação verbal).

3. Resultados de outras pesquisas realizadas no presente ano (Hettich e Karfunkel, no prelo):

seixos estriados, muito deles com forma tipicamente glacial e polidos, no tilito ao norte de Jequitaí (Fig. 8);

um esker em forma lenticular $(5 \times 20 \mathrm{~m})$ intercalado em tilito na mesma região trata-se de um quartzito estratificado de granulação média (Fig. 9);

um varvito perto de Joaquim Felício - a intercalação em dois horizontes de tilito, a presença de seixos pingados, a granulometria típica das lâminas e a estratificação cíclica muito uniforme e nítida não deixam nenhuma dúvida de que se trata realmente de um varvito (Fig. 10);

inúmeros seixos facetados e achatados e com marcas de escoriação em depósitos em Benfica, na Serra do Cipó (Fig. 11);

o tilito na Barragem do Paraúna (aquatilito) - a rocha, que apresenta xistosidade saliente, mostra o mesmo aspecto que a de Couto de Magalhães, porém os indícios de estratificação, isto é, as estruturas causadas por slumping, são mais nítidas e a quantidade de seixos e de matacões é bem maior; outros afloramentos de rocha intemperizada, na mesma região, forneceram seixos facetados ou em forma ovóide ou de flat-iron; os seixos também possuem marcas de escoriação, mas menos acentuadas do que os da Serra do Cipó.

Em resumo, a glaciação proterozóica do Macaúbas é comprovada por tilitos da composição e estrutura típica, grande distribuição desses depósitos, sedimentos glacio- 
marinhos, pavimentos estriados polidos e com caneluras, um esker, um varvito, seixos achatados, ovóides, facetados, escoriados e estriados e, finalmente, pela distribuição paleogeográfica dessas várias rochas.

Correlações Outras ocorrèncias de rochas de origem provavelmente glacial e em posição estratigráfica semelhante à do Grupo Macaúbas são:

tilitos e varvitos da Formação Topázio, em Gristalina/Goiás (Garvalho e Costa, 1968); tilitos Carandaí, do Grupo São João del Rei, no Sul de Minas Gerais (Leonardos, 1940) e

tilitos da Formação Bebedouro, na Bahia (Moraes Rego, 1930, e outros).

Essas ocorrências, freqüentemente correlacionadas com os tilitos Macaúbas, ainda não foram estudadas por nós.

Gênese do Macaúbas Superior A formação do Macaúbas Superior (camadas no topo dos depósitos glaciais), por enquanto, apenas pode ser presumida. Pflug (1967) interpretou - Macaúbas como uma formação sinorogênica. Renger (1970), que reuniu Macaúbas e Bambuí em um Supergrupo São Francisco, postulou o Macaúbas como molasse do orógeno Minas (Espinhaço). Essas interpretações poderiam referir-se apenas à parte superior, não à seqüência completa do Grupo Macaúbas. O Macaúbas Superior parece ter sido formado em água pouco profunda. Não foram encontrados depósitos semelhantes a turbiditos, mas encontraram-se calcários, não-clásticos, bem como freqüentes estratos de calcário, finos, intercalados em xistos laminados, na região de Carbonita. Porém os dados até agora obtidos ainda não são suficientes para uma interpretação genética conclusiva.

Relações entre o Macaúbas e o Bambuí Uma idade de 600 m.a. para os metassedimentos do Grupo Bambuí resultou da datação radiométrica $(\mathrm{Rb} / \mathrm{Sr})$ por Amaral e Kawashita (1967). Estromatólitos (conophyton), segundo Moeri (1972) e Cloud e Dardenne (1973), sugerem uma datação entre 950 e 1350 m.a., sendo mais prováveis as idades próximas dos 950 m.a. Recentemente, conophyton foi descoberto também na unidade basal do Macaúbas (W. U. Schöll, comunicação verbal). Faltam ainda datações radiométricas para o Macaúbas. Interdigitações faciológicas laterais entre Macaúbas e Bambuí são discutidas desde há algum tempo [Campbell et al. (1966), Pflug (1967) e Schmidt (1972)]. Schöll (1972), no entanto, mencionou interdigitações verticais e interpretou o Macaúbas como unidade mais velha. Porém a ocorrência de calcário nas camadas basais do Macaúbas no Alto Jequitinhonha, bem como a ocorrência de seixos de rocha carbonática (nos tilitos do Macaúbas) de procedência ainda desconhecida, podem sugerir contemporaneidade da sedimentação dos dois grupos.

CONCLUSÓES Aparentemente, a deposição dos sedimentos dos grupos Bambuí e Macaúbas foi contemporânea. Ocorreu uma mudança climática que provocou glaciação na área do Cráton Sanfranciscano, depois de terem sido depositadas rochas carbonáticas em bacias intracontinentais no mesmo (Bambuí) e arenitos e conglomerados com lentes de calcário na orla oriental do cráton. As camadas basais do Bambuí foram erodidas e incorporadas aos tilitos. Tais tilitos, a oeste, depositados como morenas de fundo, passam, a leste, a sedimentos glaciomarinhos. A presença de um esker e de um varvito, intercalados nos tilitos, comprova estádios de deglaciação. Após isso, houve nova mudança de clima, com deposição dos sedimentos pelíticos e químicos do Bambuí e, aqueles do Macaúbas Superior, dominantemente de fácies clástica mais grosseira. $\mathrm{Na}$ fase final da sedimentação 
ocorreu vulcanismo básico na bacia central do Macaúbas. Provavelmente, existem interdigitações entre o Macaúbas Superior e o Bambuí que, embora já mencionadas por alguns autores, ainda não foram estudadas em detalhe. Também não é conhecida, por enquanto, a procedência dos metassedimentos do Macaúbas Superior.

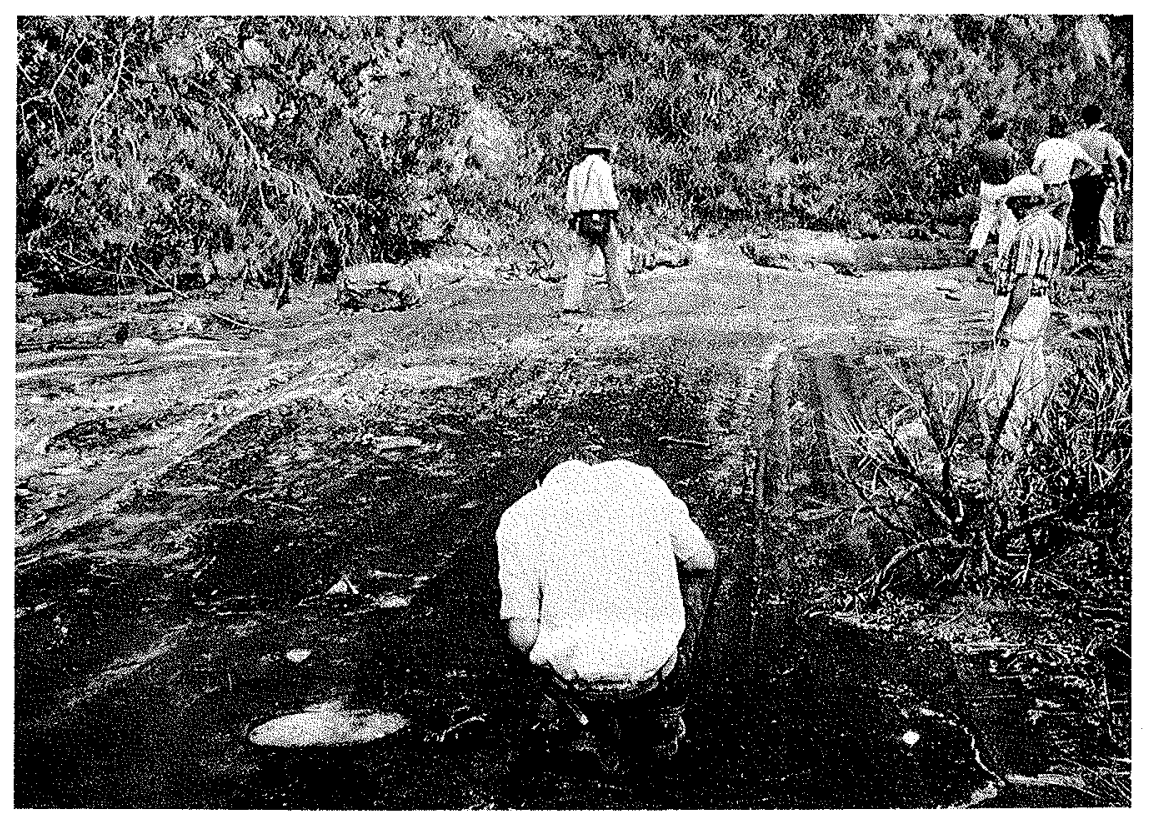

Figura 2 - Filito sobrejazendo pavimento estriado. (Localização: $10 \mathrm{~km} \mathrm{SE} \mathrm{de} \mathrm{Jequitaí)}$

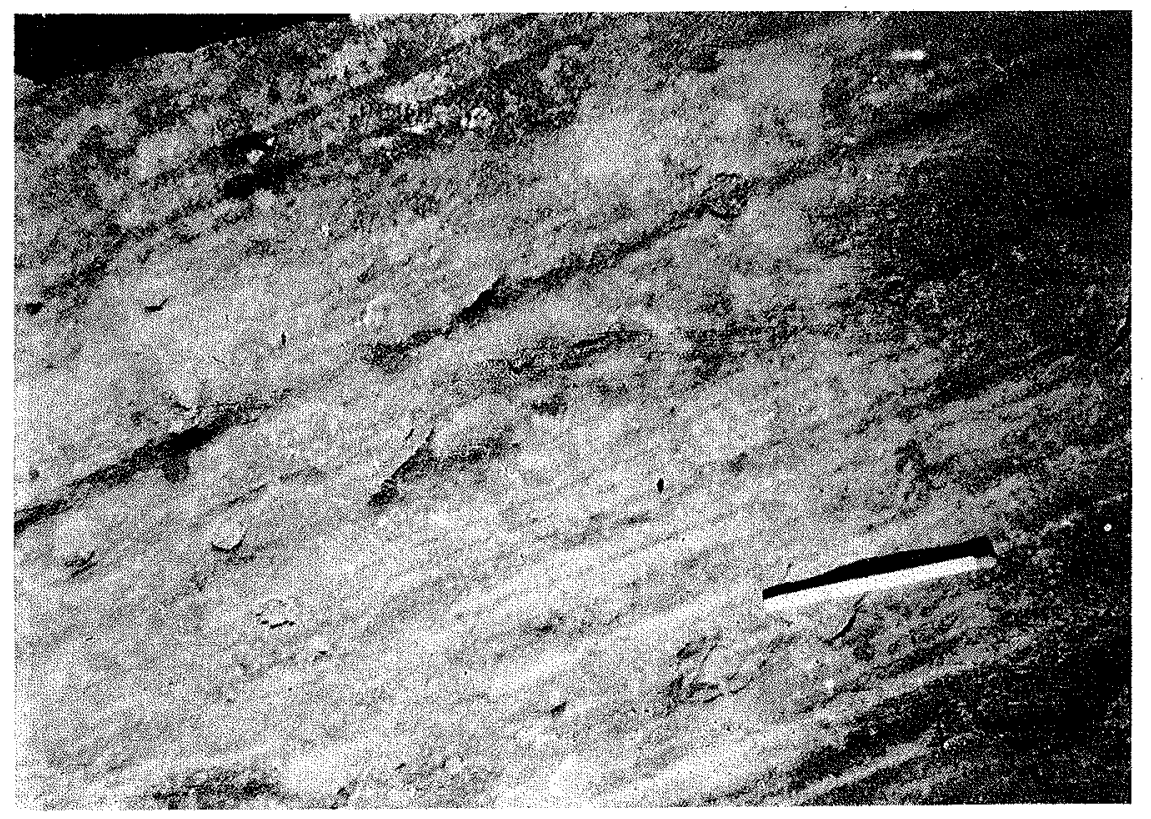

Figura 3 - Pavimento estriado. (Localização: mesma da Fig. 2) 


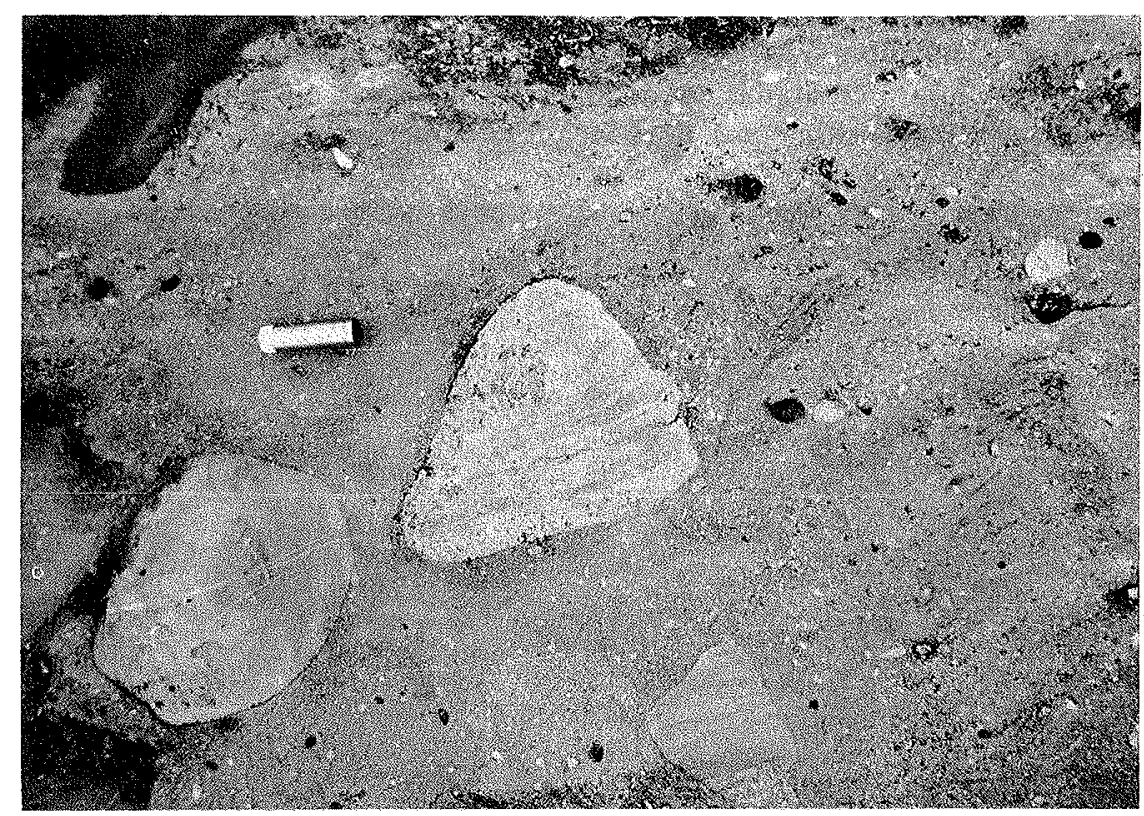

Figura 4 - Aquatilito. (Localizą̧ão: beira do Rio Manso, Couto de Magalhães)

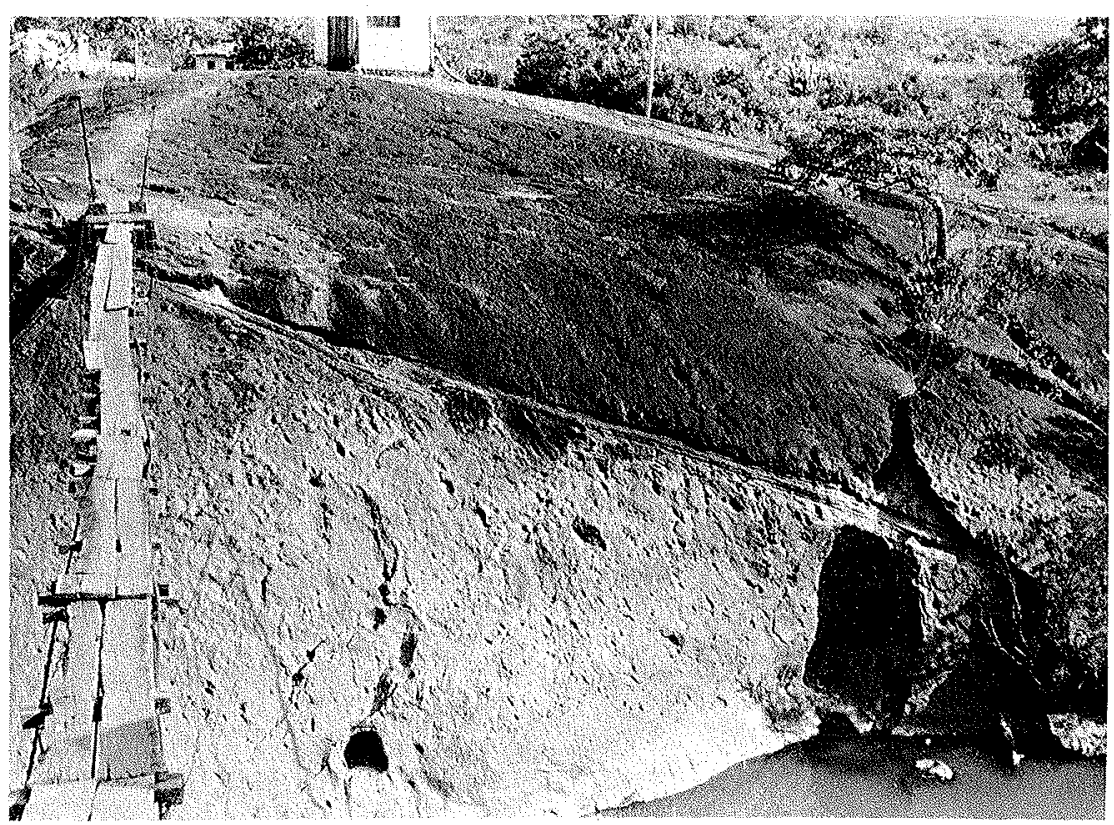

Figura 5 - Camada de quartzito estratificado intercalada em aquatilito. (Localização: mesma da Fig. 4) 


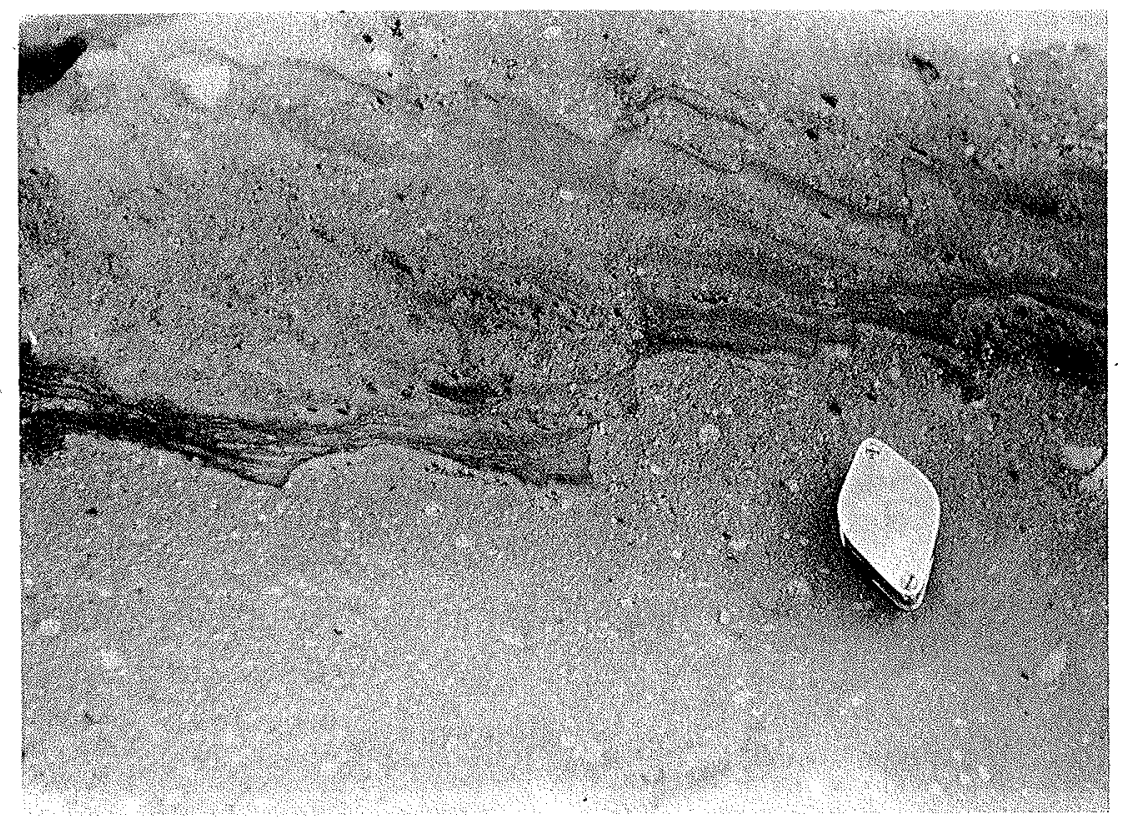

Figura 6 - Estratificação em aquatilito. (Localização: mesma da Fig. 4)

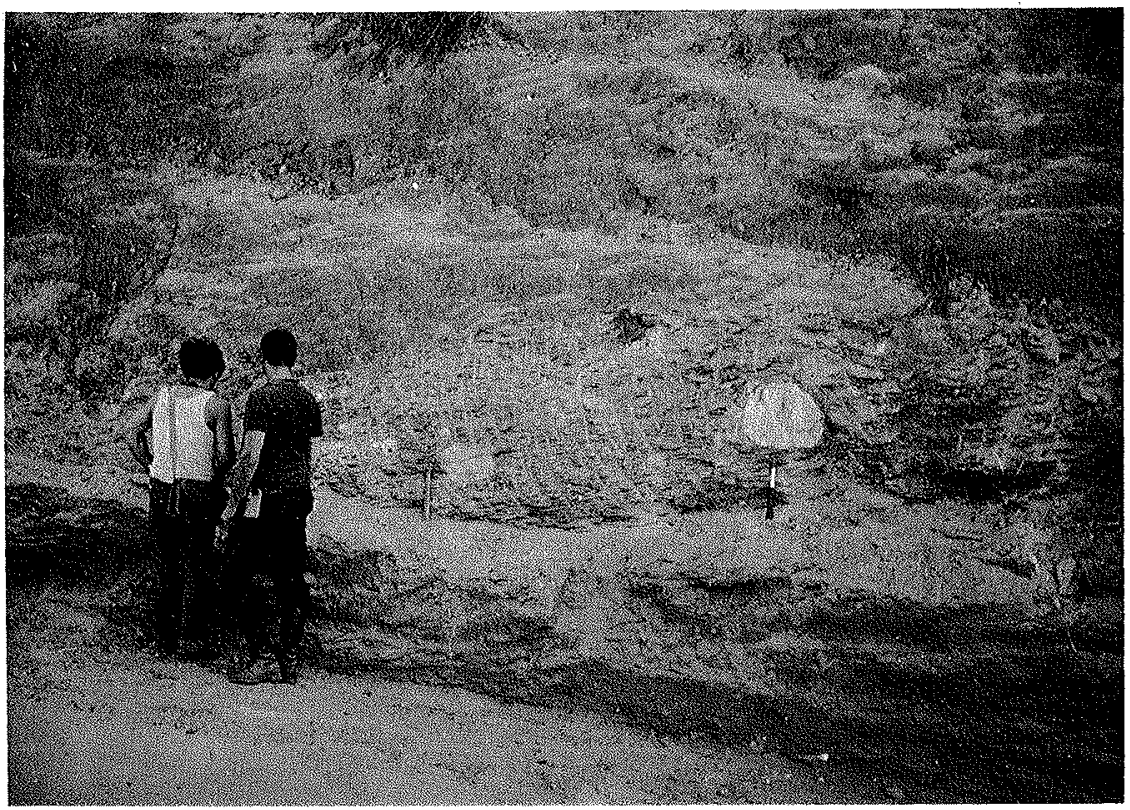

Figura 7 - Sedimentos glaciomarinhos. [Localização: MG-308, ponte sobre o Rio Araçuaí. (Foto: H. C. Kohler)] 


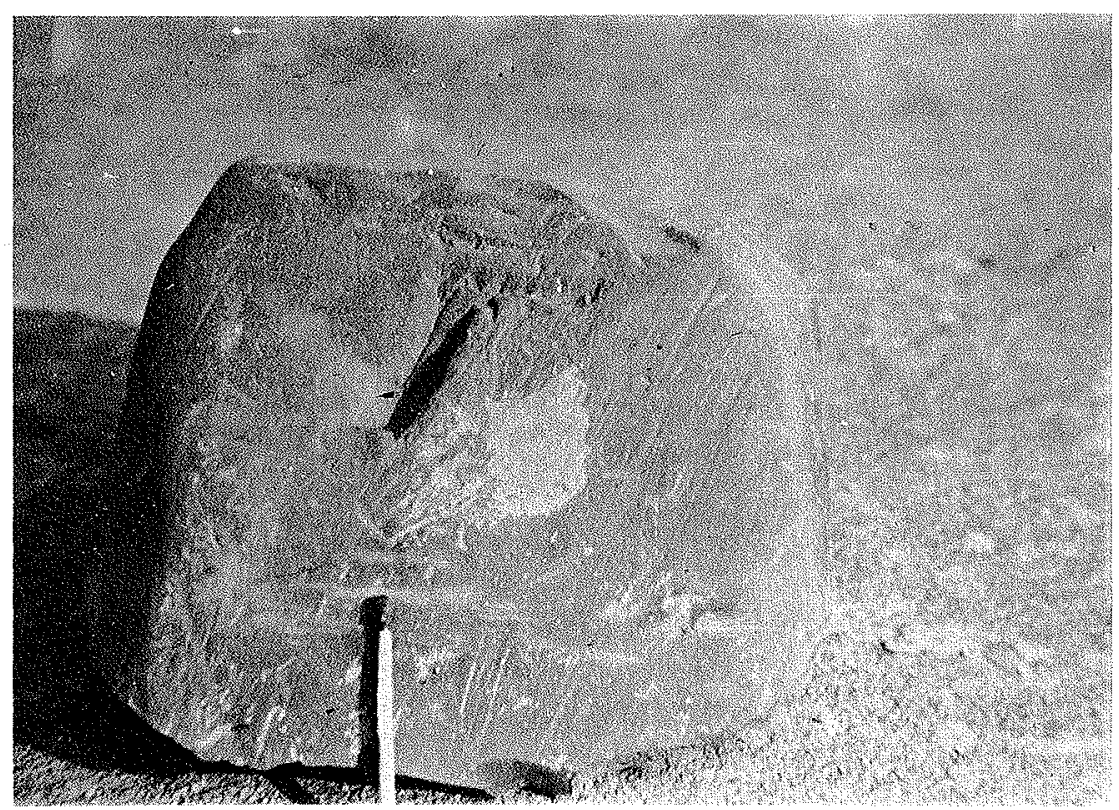

Figura 8 - Seixo estriado. (Localização: BR-365, km 67, Montes Glaros-Pirapora)

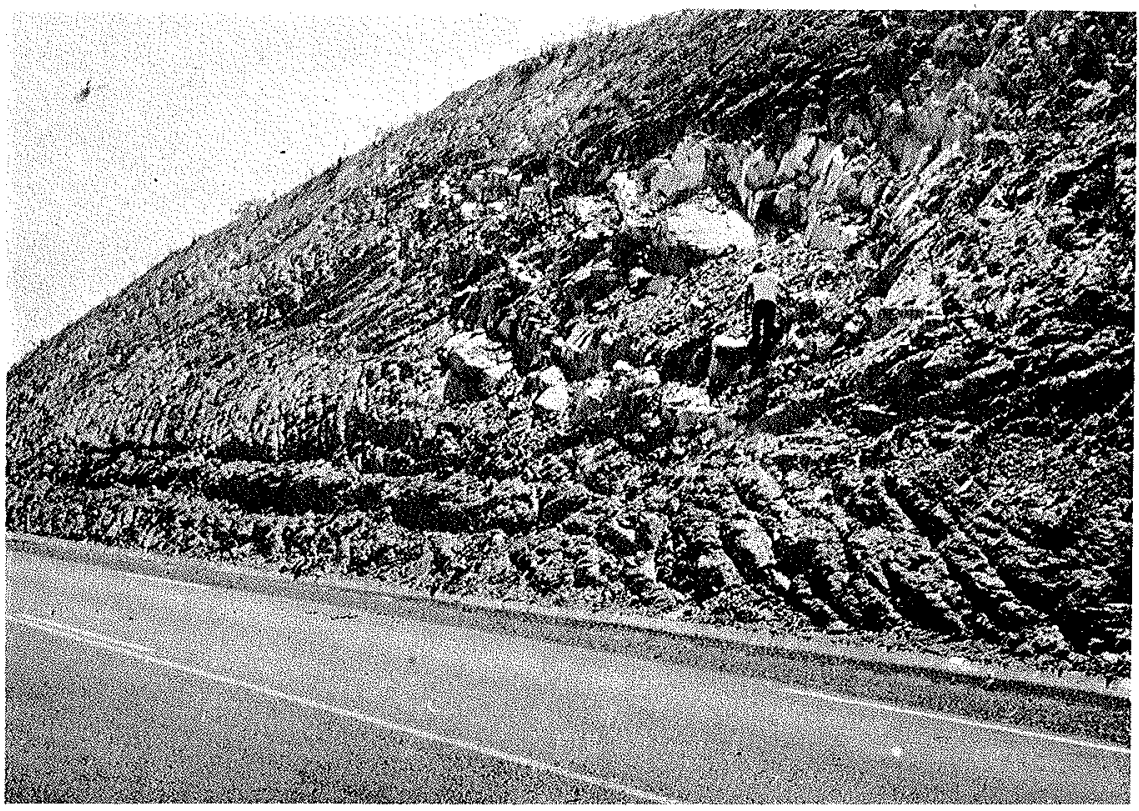

Figura 9 - Esker intercalado em tilito. [Localização: BR-365, km 68, Montes Claros-Pirapora. (Foto: H. C. Kohler)] 


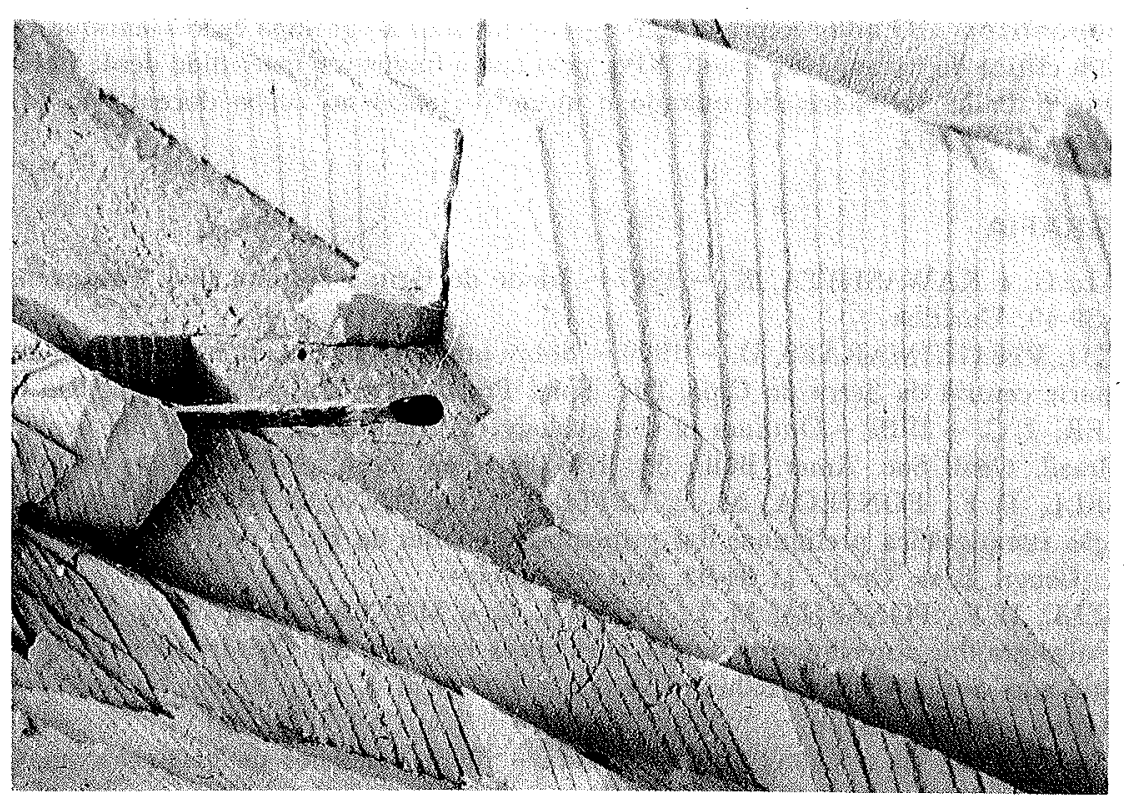

Figura 10 - Varvito. [Localização: Pedreira, $3 \mathrm{~km}$ SSW de Joaquim Felício. (Foto: J. Karfunkel)]

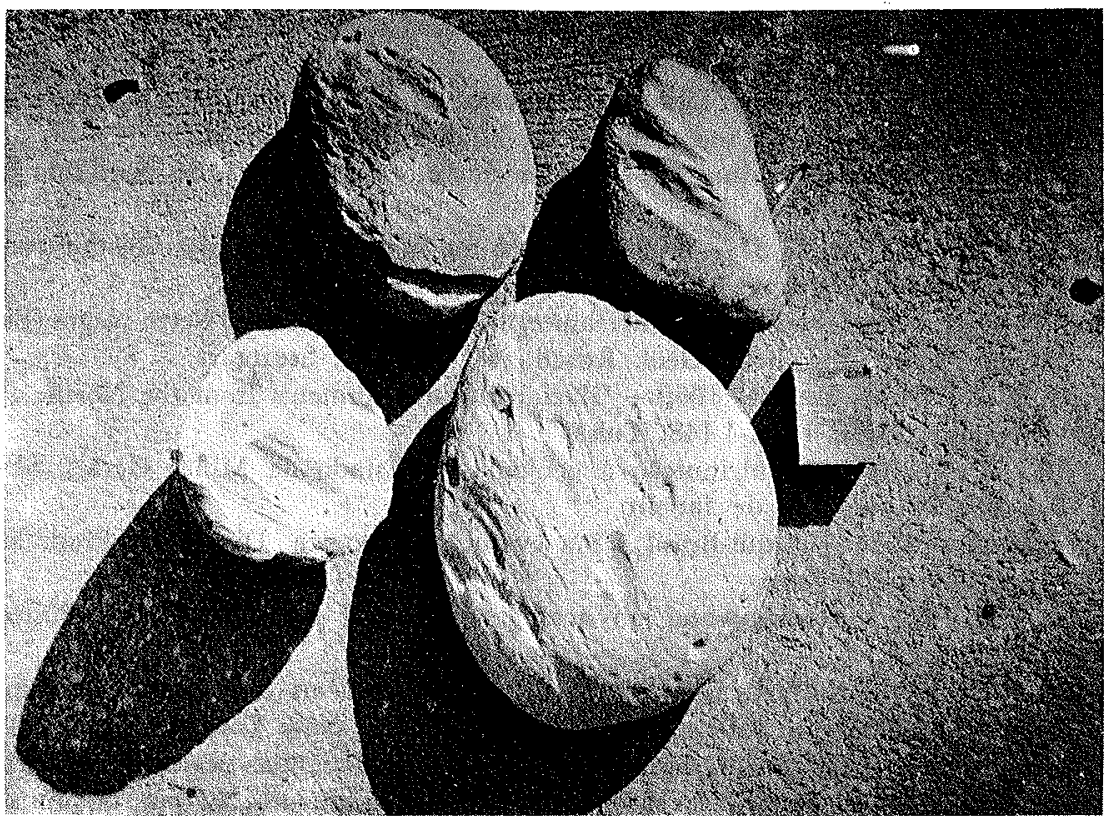

Figura 11 - Seixos escoriados. (Localizạ̧ão: Benfica, Serra do Cipó) 
Agradecimentos $\mathrm{O}$ autor expressa seus agradecimentos ao geólogo João Henrique Grossi Sad, pela leitura crítica do manuscrito, e ao GNPq, pelo apoio financeiro concedido desde julho de 1976. $O$ presente trabalho foi executado quando o autor pertencia ao corpo docente do Instituto de Geociências da UFMG.

\section{BIBLIOGRAFIA}

AMARAL, G. e KAWASHITA, K. - 1967 - Idade do Grupo Bambuí. Bol. Paranaense Geoci., 26: $39-40$, Guritiba

BELEZKIJ, V. e GUIMARÃES, D. - 1959 - Sobre uma ocorrência singular de platina e geologia da parte central da Serra do Cipó. Div. Fom. Prod. Min., Bol., 106: 77 pp., Rio de Janeiro

BRANNER, J. C. - 1919 - Outlines of the geology of Brazil to accompany the geological map of Brazil. Geol. Soc. Amer. Bull., 30: 189-338, New York

CAMPBELL, D.F., FONSEGA, M. J., LEITE L. C. e MANSANARES, V. E. - 1966 - Correlação estratigráfica preliminar das principais unidades da Bacia do Alto São Francisco. An. XX. Congr. Bras. Geol., 1: 94-95, Rio de Janeiro

CAMPBELL, D. F., FONSECA, M. J., LEITE L. G. e MANSANARES, V. E. - 1967 - Tentative stratigraphic correlation of major rock units between the Quadrilatero Ferrifero, Minas Gerais and South-Gentral Bahia. U.S.G.S., Technical Letter, Brazil Investigations BR-13 (relatório interno): $19 \mathrm{pp}$.

GARVALHO, R. T. de e COSTA, L. A. M. da - 1968 - Indícios de glaciação em Cristalina, Goiás. Eng. Miner. Metal., 48: 73-75, Rio de Janeiro

CHUMAKOW, N. M. - 1964 - Präkambrische Tillit-ähnliche Gesteine der Sowjetunion. Geol. Rdsch., 54: 83-102, Stuttgart

CLOUD, P. e DARDENNE, M. - 1973 - Proterozoic age of the Bambuí Group in Brazil. Geol. Soc. Amer., Bull., 84: 1673-1 676, New York

DERBY, O. A. - 1881 - Contribuições para o estudo da geologia do vale do São Francisco. Arch. Mus. Nac., 4: 89-119, Rio de Janeiro

DERBY, O. A. - 1888 - Über die Spuren einer carbonen Eiszeit in Südamerika. N. Jb. Min. Geol. Pälaont., 1888: 172-176, Stuttgart

DERBY, O.A. - 1905 - The geology of the diamond and carbonado washing of Bahia, Brazil. Econ. Geol., 1: 134-142, Urbana

DOTT, R. H. - 1961 - Squantum "Tillite", Massachusetts - Evidence of glaciaton or subaqueous mass movements? Bull. Geol. Soc. Amer., 72: 1 289-1 305, New York

GOMES, J. G. F. - 1949 - Contribuição ao conhecimento da geologia do Jequitaí. Rev. Esc. Minas, 4: 17-43, Ouro Preto

GÖRLER, K. e REUTTER, K. J. - 1968 - Entstehung und Merkmale der Olisthostrome. Geol. Rdsch., 57: 484-514, Stuttgart

GORLT, G. - 1972 - Fazieswechsel und Metamorphose in der westlichen Serra Negra (Espinhaço-Zone, Minas Gerais, Brasilien). Geol. Rdsch., 61: 166-201, Stuttgart

GRIGGS, G. B. e KULM, L. D. - 1969 - Glacial marine sediments from the Northeast Pacific. J. Sed. Petrology, 39(3): 1 142-1 148, Tulsa

GUIMARÃES, D. - 1931 - Contribuição à geologia do Estado de Minas Gerais. Serv. Geol. Min., Bol. 55: 36 pp., Rio de Janeiro

GUIMARÃES, D. - 1951 - Arqui-Brasil e sua evolução geológica. Div. Fom. Prod. Min., Bol. 88: 314 pp., Rio de Janeiro

HARTT, C. F. - 1870 - Geology and physical geography of Brazil., 620 pp., Boston (Fields Osgood \& Co.)

HEEZEN, B. C. e HOLLISTER, C. - 1963 - Turbidity currents and glaciation. Em A.E.M. NAIRN (ed.): Problems in Paleoclimatology., 99-109 pp., New York (Interscience)

HETTICH, M. - 1973 - Zur Stratigraphie und Genese des Macaúbas nördlich der Serra Negra, Espinhaço-Zone (Minas Gerais, Brasilien). Tese de doutoramento, 42 pp., Freiburg

HETTICH, M. - 1975 - Zur Genese des Macaúbas und Geologie des Gebietes nördlich der Serra Negra (Minas Gerais, Brasilien). Geol. Jb., B 14: 47-85, Hannover 
HETTICH, M. e KARFUNKEL, J. - 1977 - Um esker, um varvito e seixos estriados no Grupo Macaúbas, Norte Minas Gerais. Bol. Inst. Geol., Esc. Minas Ouro Preto (no prelo)

HOUGH, J. L. - 1950 - Pleistocene lithology of antarctic oceanbottom sediments. J. Geol., 58: 254-260, Chicago

ISOTTA, C. A., ROCHA-GAMPOS, A. C. e YOSHIDA, R. - 1969 - Striated pavement of the upper precambrian glaciation in Brazil. Nature, 222(5192): 466-468, London

KARFUNKEL, B. e KARFUNKEL, J. - 1975 - Fazielle Entwicklung der mittleren Espinhaço-Zone mit besonderer Berücksichtigung des Tillit-Problems (Minas Gerais/Brasilien). Tese de doutoramento, 86 pp., Freiburg

LEONARDOS, O. H. - 1940 - Tilito metamórfico de Garandaí, Minas Gerais. Ann. Acad. Bras. Ci., 12: 243-259, Rio de Janeiro

LISBOA, M. A. R. - 1906 - Ocorrência de seixos facetados no Planalto Central Brasileiro. An. Esc. Min. Ouro Preto, 8: 24-40

MENARD, H. W. - 1963 - Pleistocene and recent sediment from the floor of the Northeastern Pacific Ocean. Geol. Soc. Amer., Bull., 64: 1279-1294, New York

MOERI, E. - 1972 - On a columnar stromatolite in the precambrian Bambuí Group of Central Brazil. Ecl. geol. Helv., 65: 185-195, Basel

MORAES, L. J. de - 1929 - Geologia da região Diamantina, Estado de Minas Geraes. Serv. Geol. Min., Rel. Annual, 1928: 29-34, Rio de Janeiro

MORAES, L. J. de - 1932 - Área occupada pela Formação Macahubas no norte de Minas Geraes. Ann. Acad. Bras. Sci. 4: 11-114, Rio de Janeiro

MORAES, L. J. de, BARBOSA, O., LISBOA, J. M. A., LACOURT, F. e GUIMARÃES, D. - 1937 - Geologia econômica do norte de Minas Geraes. Serv. Fom. Prod. Min., Bol. 19: 192 pp., Rio de Janeiro

MORAES, L. J. de, e GUIMARÃES, D. - 1930 - Geologia da região diamantífera do norte de Minas Geraes. Ann. Acad. Bras. Sci., 2: 153-186, Rio de Janeiro

MORAES REGO, L. F. de - 1930 - Glaciação eopaleozóica no centro do Brasil. Ann. Acad. Bras. Sci., 2: 109-112, Rio de Janeiro

PFLUG, R. - 1963 - Contribuição à paleogeografia da Serra do Espinhaço (Quartzitos da região de Diamantina, Minas Gerais). Div. Geol. Min., Bol. 119: 16 pp., Rio de Janeiro

PFLUG, R. - 1965 - A geologia da parte meridional da Serra do Espinhaço e zonas adjacentes, Minas Gerais, Div. Geol. Min., Bol. 226: 55 pp., Rio de Janeiro

PFLUG, R. - 1967 - Die präkambrische Miogeosynklinale der Espinhaço-Kordillere, Minas Gerais, Brasilien. Geol. Rdsch., 56: 825-844, Stuttgart

PFLUG, R. e SCHÖLL, W. U. - 1975 - Proterozoic glaciations in eastern Brazil : a review. Geol. Rdsch., 64: 287-299, Stuttgart

RAMOS, J. R. de A. e MACIEL, A. C. - 1974 - Prospeç̧ão de urânio no Brasil 1970/1974. CNEN, Bol. 4, p., 50, Rio de Janeiro

RENGER, F. - 1970 - Fazies und Magmatismus der Minas-Serie in der südlichen Serra do Espinhaço, Minas Gerais, Brasilien. Geol. Rdsch., 59: 1 253-1 292, Stuttgart

SCHERMERHORN, L. J. G. - 1974 - Late precambrian mixtites: glacial and/or nonglacial? Amer. J. Sci., 274: 673-821, New Haven

SCHMIDT, H. L. - 1972 - Fazieswechsel in der São Francisco-Serie (Bambuí) bei Bocaiúva, Espinhaço-Zone, Minas Gerais/Brasilien. Beih. Geol. Jb., 121: 59-94, Hannover

SCHÖLL, W.U. - 1972 - Der südwestliche Randbereich der Espinhaço-Zone, Minas Gerais, Brasilien. Geol. Rdsch., 61: 201-216, Stuttgart

SCHWARZBACH, M. - 1974 - Das Klima der Vorzeit. 380 pp., Stuttgart (Enke)

TOIT,A. L. de - 1954 - The geology of South Africa (S. H. HAUGHTON, ed.), 625 pp., Edinburgh (Oliver \& Boyd)

WILLIAMS, H. E. - 1930 - Estudos geológicos na Chapada Diamantina. Serv. Geol. Min., Bol. 44: 16 pp., Rio de Janeiro 